\title{
Microstructural development and densification during hipping of ceramics and metals
}

\author{
W. A. Kaysser, M. Aslan, E. Arzt, M. Mitkov, and G. Petzow
}

Prediction of deformation behaviour during hipping is often difficult because data on complex material properties are required but are not usually available measurement of the deformation of a single sphere is proposed as a direct and simple method of predicting hipping behaviour. For C1018 steel, copper, and AP1 nickel superalloy, the predictions made from deformation experiments with single spheres were in good agreement with measured hipping behaviour at hipping densities $<93 \%$ theoretical. In addition, the creep parameters, such as the exponent $n$ for the power law creep relation, of the powder material itself were measured during single sphere deformation. During hipping of C1018 in the density range above $90 \%$, the use of lower pressures, which is structural development and densification during the final stage of hipping are determined by relatively large pores. These large pores may result from irregularities in the initial powder packing and are still present when areas of initially well packed particles were completely densified. Quantitative measurements of this effect in $\mathrm{C} 1018$ were supported by two dimensional simulations of the densification process. Additional observations of AP1, C1018, and W(Ni) emphasised the importance of the differential deformation of individual particles and grain growth on microstructural development during hipping.

$\mathrm{PM} / 0452$

(C) 1988 The Institute of Metals. Contribution to the PM Group Conference on 'Shaping and compacting' held on 19-21 October 1987 at Eastbourne. Dr Kaysser, Dr Aslan, Dr Arzt, and Professor Petzow are at the Max-PlanckInstitut für Metallforschung, Institut für Werkstoffwissenschaften, Stuttgart, FRG, and Dr Mitkov is in the Institute Boris Kidrič, Belgrade, Yugoslavia. from the literature. From the present work, favoured for economic reasons, showed that micro-

experimental verification. In this paper a simple experimental method is presented which allows prediction of hipping behaviour at lower densities and also provides some of the material data required for the complex calculation of hipping diagrams.

A major application of hipping is the production of dense and homogeneous materials. Hence, it is of importance to be aware of effects which may lead to residual pores or inhomogeneous microstructural development during hipping. A special challenge in this respect is posed by the new, economically advantageous high volume hipping or sinterhipping systems which operate at pressures below $60 \mathrm{MPa}$. The low pressure and the microstructure of the materials, which are presintered to close porosity, require an increased awareness of features that may constitute or lead to defects.

Microstructural observations during the hipping of C1018 steel, API (a nickel base superalloy), and presintered $\mathrm{W}(\mathrm{Ni})$ are presented; defects during hipping are found to develop from deviations of the initial particle distribution from ideal random dense packing, as well as from differential individual deformation of individual particles and from pore-grain boundary separation in the presintered microstructures.

\section{RELATION BETWEEN DEFORMATION OF SINGLE SPHERES AND HIPPED SAMPLES}

Single powder spheres were uniaxially deformed under a controlled load $f$, as shown schematically in Fig. 2. For the calculation it was assumed that the material in the deformation zones (dark areas) is distributed homogeneously on the free surface of the particles, i.e. the radius $R$ of the particle is increasing during deformation. The particle radius $R$ and the radius $x$ of the contact area are connected to the reduction $h$ of the distance between the particle centre and the contact area by the expressions

$$
\begin{aligned}
& R=\left\{\left[\frac{2}{3} R_{0}^{3}+\frac{1}{3}\left(R_{0}-h\right)^{3}\right] /\left(R_{0}-h\right)\right\}^{1 / 2} \text {. . . . . } \\
& \text { and } \\
& x=\left\{2\left[h+\left(R-R_{0}\right)\right] R-\left[h+\left(R-R_{0}\right)\right]^{2}\right\}^{1 / 2}
\end{aligned}
$$

Table 1 Descriptions of densification rate, as characterised by centre approach rate $y$, during hipping*

law creep, Nabarro-Herring creep, Coble creep, grain boundary sliding in the particles, and grain boundary and bulk diffusion at the particle contacts can all contribute to densification (Fig. 1). ${ }^{1-3}$ Which of these mechanisms dominates shrinkage and neck growth rate depends on a number of parameters related to the powder (size, grain size, instantaneous geometry, bulk properties, interface properties) and to processing (pressure, temperature, time). The neck growth and centre approach rates have been described by the equations given in Table 1 . To ease the engineer's choice of hipping parameters required for densification of a particular material, hipping diagrams were developed some years ago. ${ }^{7.8}$ However, the construction of these diagrams requires knowledge of a variety of materials data, which is often not available. Because of the tedious and time consuming character of hipping experiments, the theoretical predictions still lack sufficient
Coble creep ${ }^{1,4} \quad$ Nabarro-Herring creep ${ }^{5,6}$

$$
\dot{y}=\frac{4}{x^{2}} \frac{\delta D_{\mathrm{b}}+\rho D_{\mathrm{v}}}{k T} \Omega p_{\mathrm{err}} \quad \dot{y}=8 \cdot 2 x \frac{1}{k T \bar{G}^{2}}\left(D_{\mathrm{v}}+\frac{\pi \delta D_{\mathrm{b}}}{\bar{G}}\right) \Omega p_{\mathrm{crr}}
$$

Power law creep ${ }^{\top}$

$$
\dot{y}=1 \cdot 8 x \dot{\varepsilon}_{0}\left(\frac{p_{\text {eff }}}{3 \sigma_{0}}\right)^{n}
$$

* $D_{\mathrm{b}}=$ grain boundary diffusion coefficient; $D_{\mathrm{r}}=$ lattice diffusion coefficient; $\bar{G}=$ average grain size; $k=$ Boltzmann constant; $n=$ power law creep exponent; $p_{\text {eff }}=$ effective pressure at particle contact; $T=$ absolute temperature; $x=$ radius of particle contact area; $\delta=$ grain boundary thickness; $\dot{\varepsilon}_{0}=$ power law creep parameter; $\rho=$ radius of curvature of neck; $\sigma_{\mathfrak{a}}=$ power law creep parameter; $\Omega=$ atomic volume. 


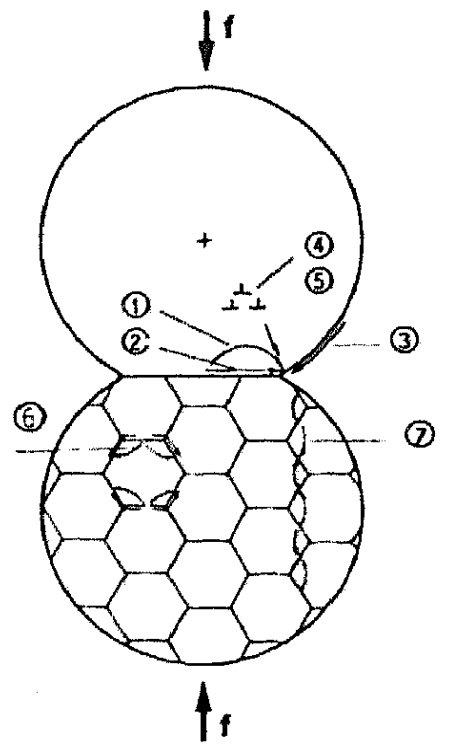

1 BUI.K DIFFUSION

2 GRAIN BOUNDARY OIFFUSION

3 SURFACE DIFFUSION

4 PLASTIC DEFORMATION

5 POWER LAN CREEP

6 DIFFUSIONAL CREEP

(NH-C CREEP)

7 GRAIN BOUNDARY SLIDING

1 Transport mechanisms operating during hipping

The resulting pressure $p$ at the contact zone is

$$
p=\frac{f}{\pi x^{2}}
$$

The deformation of the single sphere between two parallel plates was transformed into an equivalent 'hipped density' $D$. Taking into account the increasing number $Z$ of contacts per particle during densification ${ }^{9}$ the relation

$$
D=\frac{D_{0}}{1-\frac{1}{3} R_{0}^{-3}\left[\left(7 \cdot 3+8 \cdot 6 \frac{x^{2}}{R_{0}^{2}}\right) h^{2}\left(3 R_{0}-h\right) 0 \cdot 3\right]}
$$

was obtained, where $D_{0}$ is the initial relative density. It was later found, however, that the empirical relation

$$
D=D_{0}+2 \frac{h}{R_{0}}\left(1+\frac{h}{R_{\mathrm{o}}}\right)
$$

describes equally well the relation between the deformation of a single sphere between two plates and the equivalent hipped density.

The relation between the external hipping pressure $p^{*}$ and the average force $f^{*}$ on a single particle during hipping is given by ${ }^{9.10}$

$$
p^{*}=\frac{Z D}{4 \pi R_{0}^{2}} f^{*} \text {. }
$$

This relation was used to transform the force $f$ on the single particle into an equivalent external hipping pressure $p^{*}=p_{\text {eq }}$ by setting $f^{*}=f$.

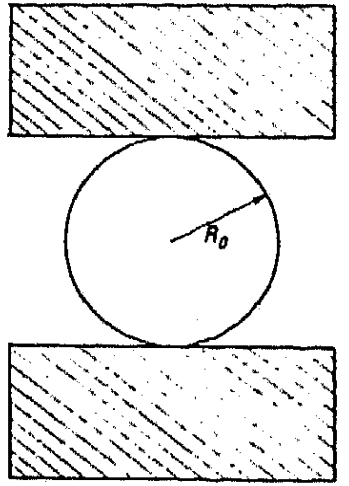

Initial condition

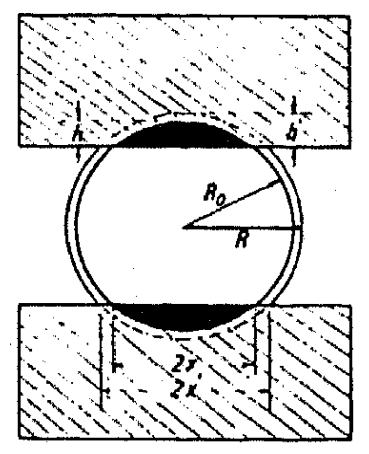

Deformation condition
2 Schematic diagram of deformation of sphere between two parallel plates

\section{COMPARISON BETWEEN DEFORMATION OF SINGLE SPHERES AND HIPPED \\ SAMPLES}

Powders with high sphericity and a narrow size distribution (range $<25 \mu \mathrm{m}$ ) were placed in glass containers. After evacuation to $0 \cdot 1 \mu \mathrm{Pa}$ the containers were sealed and hipped in a minihipper. For comparison, single spheres were deformed in a precision dilatometer under loads between $0 \cdot 1$ and $1 \mathrm{~N}$.

Figure $3 a$ shows the hipped density of steel C1018 samples after hipping at $1000 \mathrm{C}$ for 1 and $20 \mathrm{~min}$ at different external pressures. Various hipped densities calculated from the results of single sphere dilatometer experiments are included for comparison. The agreement between the predictions on the basis of the single sphere experiments and the results from the hipped samples is excellent. A similar comparison for copper also indicated good accuracy of the prediction, up to hipped theoretical densities of 0.93 (Fig. $3 b$ ). At higher densities the deformation of the two single sphere contacts is no longer comparable to the deformation of the material in the vicinity of pores in the hipped body. The hipped densities of copper samples that confirm the data predicted from the

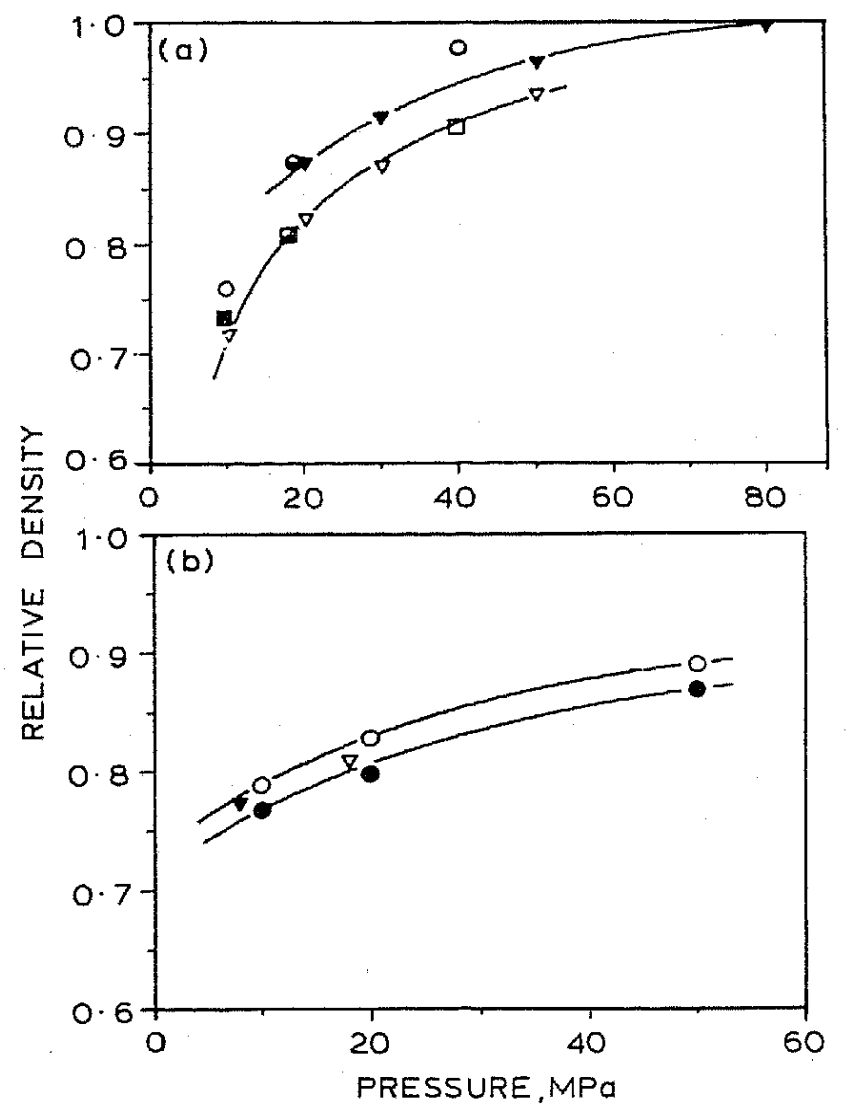

a hipped densities for C1018 (particle size range 100-125 $\mu \mathrm{m}$ ) after $\nabla 1$ and $\nabla 20 \mathrm{~min}$ at $1000^{\circ} \mathrm{C}$ and calculated densities from single sphere deformation measurements (particle size $180 \mu \mathrm{m}): f=0.45 \mathrm{~N} \quad\left(p_{\text {eq }}=40 \mathrm{MPa}\right), \square 1 \mathrm{~min}, \quad \bigcirc 20 \mathrm{~min}$; $f=0.25 \mathrm{~N}\left(p_{\text {eq }}=18 \mathrm{MPa}\right), \quad 1 \mathrm{~min}, \bigcirc 20 \mathrm{~min} ; f=0.16 \mathrm{~N}$ $\left(p_{\text {eq }}=8 \mathrm{MPa}\right), 1 \mathrm{~min}, 20 \mathrm{~min} ; b$ hipped densities for copper obtained after hipping at 750 and $O 850^{\circ} \mathrm{C}$ for $20 \mathrm{~min}$ (particle size range $150-200 \mu \mathrm{m}$ ) and calculated densities from single sphere deformation measurements $(t=20 \mathrm{~min}): \nabla f=0.15 \mathrm{~N}(p=8 \mathrm{MPa})$, particle size $180 \mu \mathrm{m}$, grain size $10 \mu \mathrm{m} ; \nabla f=0.30 \mathrm{~N}\left(p_{\text {eq }}=18 \mathrm{MPa}\right)$, particle size $180 \mu \mathrm{m}$, grain size $10 \mu \mathrm{m}$

3 Comparison of hipped densities calculated from single sphere dilatometer measurements and obtained after hipping C1018 steel and copper: $f$ and $p_{\text {eq }}$ describe force on single sphere in dilatometer and equivalent hipping pressure 


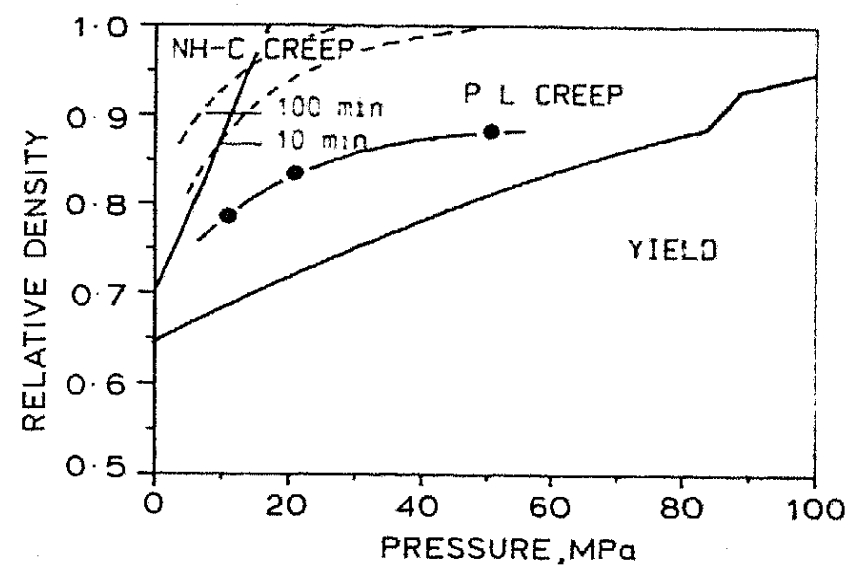

4 Hipping diagram for copper at $850^{\circ} \mathrm{C}$ calculated after Arzt et al. ${ }^{7}$ (mean particle size $175 \mu \mathrm{m}$, grain size $10 \mu \mathrm{m})$ : plotted data show density of hipped copper samples $\left(850^{\circ} \mathrm{C}, 20 \mathrm{~min}\right.$, particle size range $\left.150-200 \mu \mathrm{m}\right)$

dilatometer experiments have also been included in a hipping diagram, calculated after Arzt et al. ${ }^{7}$ (Fig. 4). The isochrones of the hipping diagram suggest a stronger stress sensitivity of the deformation rate than that measured. As a consequence, the hipped density after hipping for $20 \mathrm{~min}$ at $850^{\circ} \mathrm{C}$ is much lower than predicted in the diagram. Whatever the metallurgical reason for the discrepancy between the hipping diagram and the measured behaviour may be, this example shows that the single sphere measurements are a valuable tool for individual 'non-ideal' materials.

It is possible to investigate particles with particular properties. Copper spheres of the same size but different internal grain size $(10,40$, and $180 \mu \mathrm{m})$ were measured in the dilatometer at $800^{\circ} \mathrm{C} \mathrm{(Fig.} \mathrm{5).} \mathrm{It} \mathrm{is} \mathrm{obvious} \mathrm{that} \mathrm{the}$ internal grain size of the powder particles has a considerable influence on the deformation behaviour and on the hipping densification. It is also possible to measure specific properties of the material, for example the creep exponent. The slope of the straight line in the $\log -\log$ plot of deformation rate versus effective stress in Fig. 6 directly gives the creep exponent $n$. For $\mathrm{C} 1018$ the measured value is $4 \cdot 2$. This compares well with the values of 4.5 given in the literature, which were measured by other techniques."

The dilatometer experiments emphasise the extent of densification during heating. During fast heating deforma-

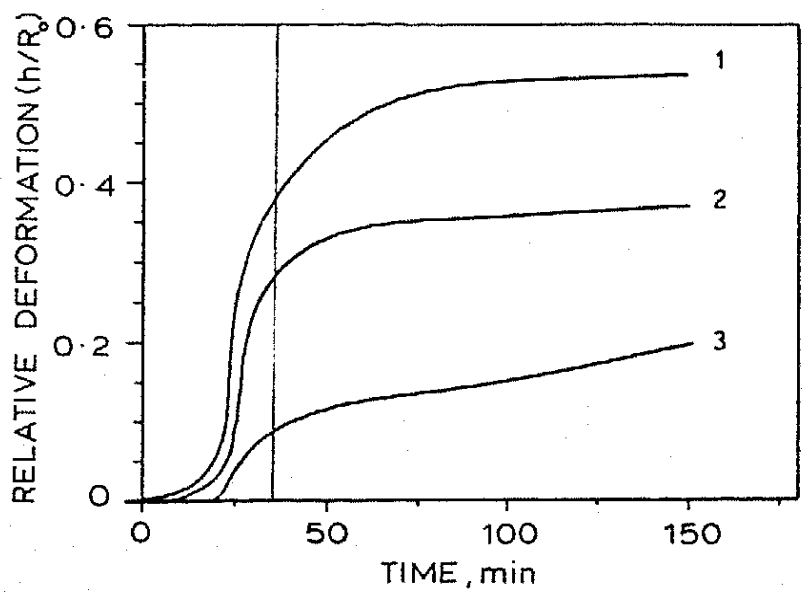

1: grain size $10 \mu \mathrm{m} ; 2$ : grain size $40 \mu \mathrm{m} ; 3$ : single crystal

5 Relative deformation of copper spheres at $800^{\circ} \mathrm{C}$ (particle size $2 R_{0}=180 \mu \mathrm{m}$, force $f=0.6 \mathrm{~N}$ ), showing influence of inner grain size on deformation behaviour: heating rate $30 \mathrm{Kmin}^{-1}$

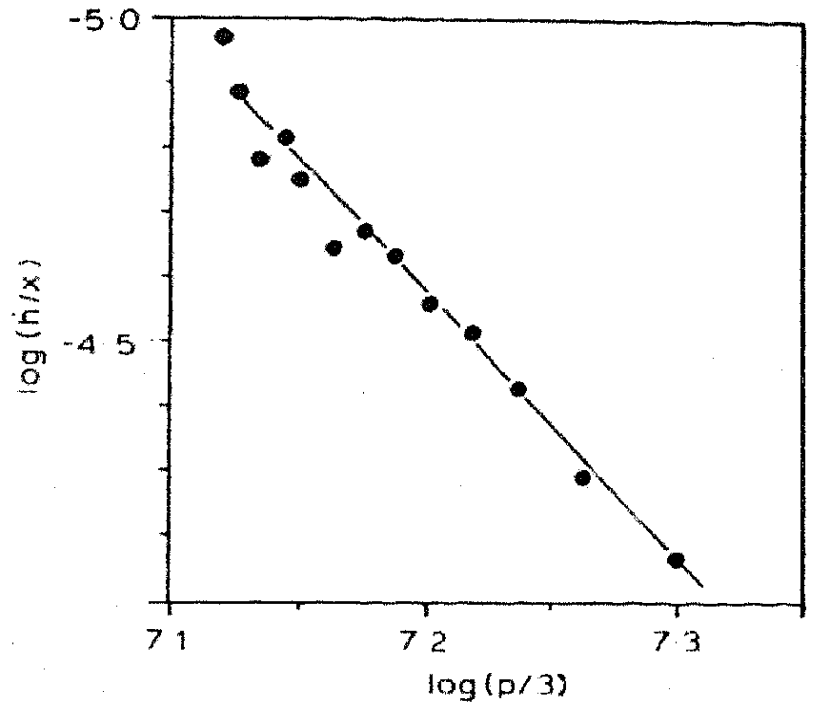

6 Stress dependence of deformation rate of $C 1018$ steel spheres at $1000^{\circ} \mathrm{C}$ : particle size $2 R_{0}=180 \mu \mathrm{m}$; force $f=0.25 \mu \mathrm{m}$

tion is mainly due to plastic deformation, whereas during slow heating the deformation rate due to power law creep exceeds that due to plastic deformation. Figure 7 shows the deformation of AP1 spheres at loads between 0.07 and $0.26 \mathrm{~N}$, which is equivalent to hipping pressures between 8 and $40 \mathrm{MPa}$. The predicted hipped density is in good agreement with the values for AP1 at low pressures and short isothermal hipping times reported by Mitkov et al. ${ }^{\text {1 }}$

\section{INITIAL PARTICLE ARRANGEMENT AND PORE SIZE DISTRIBUTION DURING FINAL STAGE HIPPING}

Figure 8 shows a sequence of microstructures of $\mathrm{C} 1018$ (100 $\mu \mathrm{m}$ powder) hipped to relative densities between 0.70 and 0.99. At densities below 0.9 the section shows areas of higher and lower particle density. Most of the virtual porosity variation is a result of the two dimensional sectioning of the poured spheres. Some of the larger pores may indicate, however, packing inhomogeneities which result in a few pores that are larger than should be present in an ideal random arrangement. At hipped densities of 0.97 and 0.99 a small number of large pores is still present. An unetched microstructure of the sample (Fig. $8 d$ ) clearly

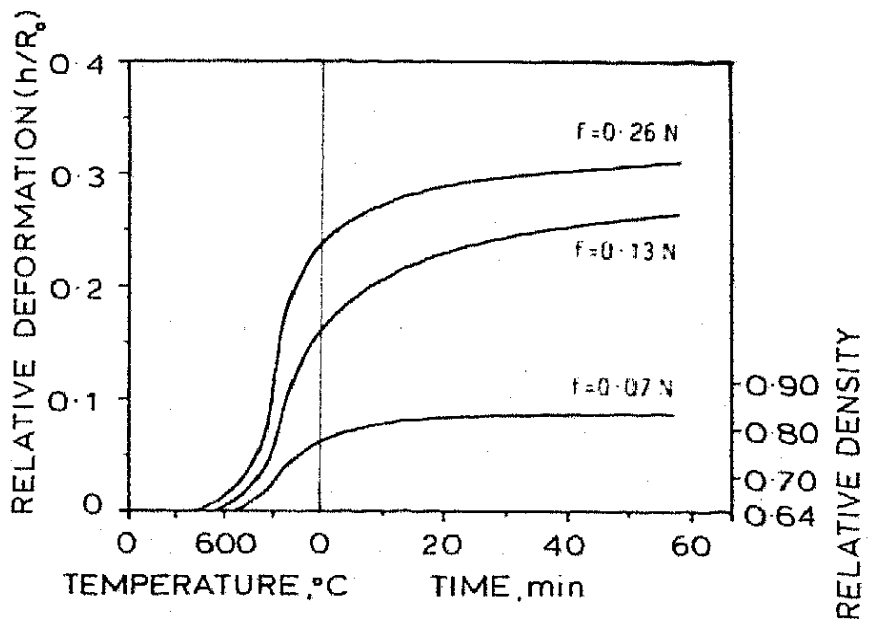

7 Deformation of API superalloy spheres during heating to $1180^{\circ} \mathrm{C}$ at $40 \mathrm{~K} \mathrm{~min}^{-1}$ and subsequent isothermal annealing under various applied forces $f:$ particle size $140 \mu \mathrm{m}$ 


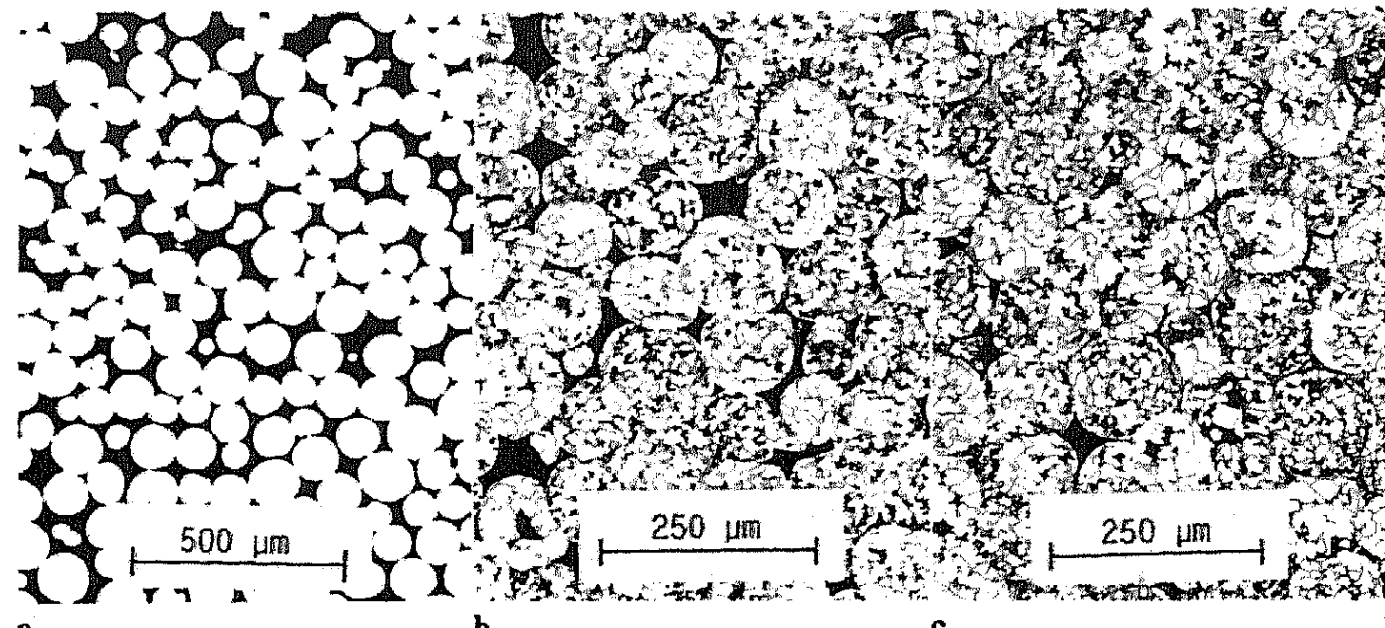

a

b

c

d

$a 1 \mathrm{~min}, 1 \mathrm{MPa}, D=0 \cdot 66 ; b 10 \mathrm{~min}, 50 \mathrm{MPa}, D=0.95 ; c 20 \mathrm{~min}, 80 \mathrm{MPa}, D=0.99: d 20 \mathrm{~min}, 80 \mathrm{MPa}$ (unetched)

8 Microstructure of $\mathrm{C} 1018$ steel after hipping under various conditions at $1000^{\circ} \mathrm{C}: D$ is final relative density; particle size range $100-125 \mu \mathrm{m}$

shows relatively large $(\sim 40-50 \mu \mathrm{m})$ pores. The fine regular porosity has disappeared between most particles.

The pore size distribution was determined by lineal analysis. At a relative density of $0.99,40 \mu \mathrm{m}$ chord length pores occurred with a frequency of $\sim 1 \%$, indicating the presence of a small number of pores with sizes of the order of the initial particle radius, even in a material that is often considered as dense. The presence of comparatively large pores at very low porosities would be expected to influence the mechanical properties of hipped materials considerably. The fatigue behaviour of high strength materials is known to be sensitive to pores of this size. These residual pores can also be found in material hipped from much finer starting powders, such as ceramics. If the agglomerates do not disintegrate sufficiently during the initial stages of hipping a small number of large pores may remain in the dense ceramic matrix after hipping. Since these large pores are potential nuclei for crack initiation they are likely to decrease the Weibull modulus of the ceramic materials considerably.

The residual pores are thought to result from small packing faults in the initial powder arrangement. The influence of small initial packing faults is demonstrated in the two dimensional model shown in Fig. 9. Two particle arrangements are shown. Three particles forming an equilateral triangle were assumed to undergo centre approach during hipping by removal of material from the contact areas. One half of the removed material was spread virtually uniformly on the free surface of the pore between the particles. The same procedure was carried out for four particles forming a square. At the same centre approach the four particle arrangement still shows a relatively large pore one third of the particle radius in size. It must be assumed that a certain number of similar packing defects also exist in powder compacts, i.e. in three dimensional arrangements, even after very careful processing. As a consequence, a certain number of comparatively large pores has to be eliminated at the very end of the final stage of hipping. At this stage the present models assume a much larger number of much finer pore to be present.

\section{DEFORMATION OF INDIVIDUAL SPHERES}

Figure 10 shows the microstructure of API after hipping at $1120^{\circ} \mathrm{C}$ for $20 \mathrm{~min}$ at $50 \mathrm{MPa}$. The particle size range was between 125 and $160 \mu \mathrm{m}$ and the residual porosity $<0.5 \%$. Figure $10 a$ shows some particles with a much coarser grain size than the majority of the specimen. At higher magnification the coarse grained particles reveal a high degree of residual sphericity, i.e. the particles appear to have been only modestly deformed during hipping (Fig. 10b). The conclusion that reduced deformation of the AP1 particles resulted in the formation of coarse grains was supported by the microstructural development in an 'accidental' area of the hipping capsule. Figure $10 \mathrm{c}$ shows the microstructure in the corner of the cylindrical steel encapsulation. The powder particles have been only slightly deformed due to insufficient deformation of the steel capsule. The reduced isostatic pressure is also indicated by expansion of the enclosed argon bubbles. The slightly deformed superalloy particles exhibit coarse grains compared to the fine grained microstructure of the densified areas of the sample. A small number of particles distinguished from the rest of the material by a very coarse grain size was also found in hipped C1018.

The fact that all particles in the area of reduced deformation shown in Fig. $10 c$ developed a coarse grain microstructure suggests that the differential microstructural development of these particles in a fine grained matrix does not primarily result from deviations in their chemical composition or initial microstructure. The differential microstructural development can be traced back to differences in the deformation of individual particles. Different degrees of deformation may arise from particle size differences. If a larger particle is surrounded by smaller particles, as shown schematically in Fig. $11 a$,

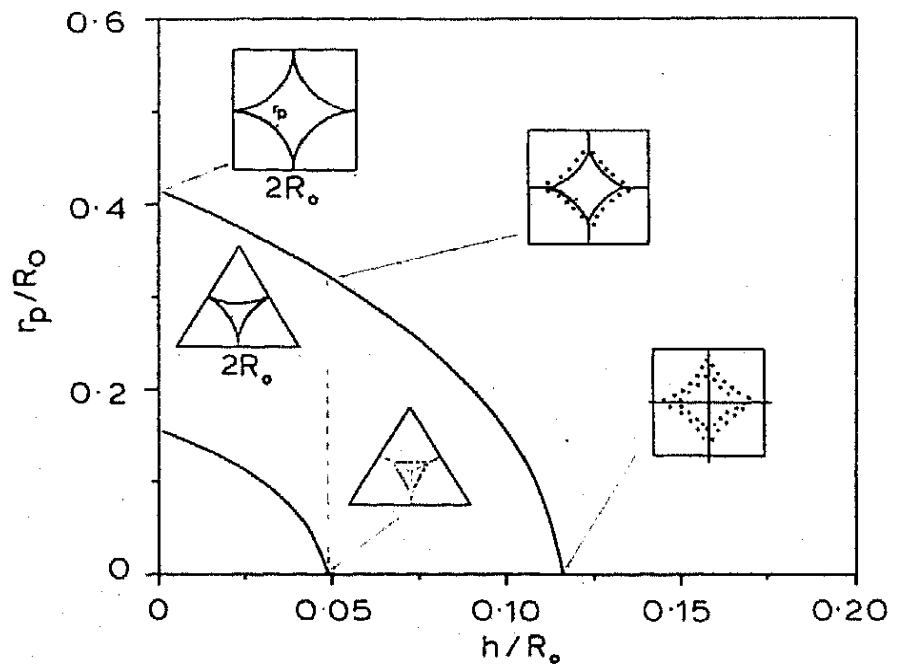

9 Two dimensional densification model of two typical particle arrangements 


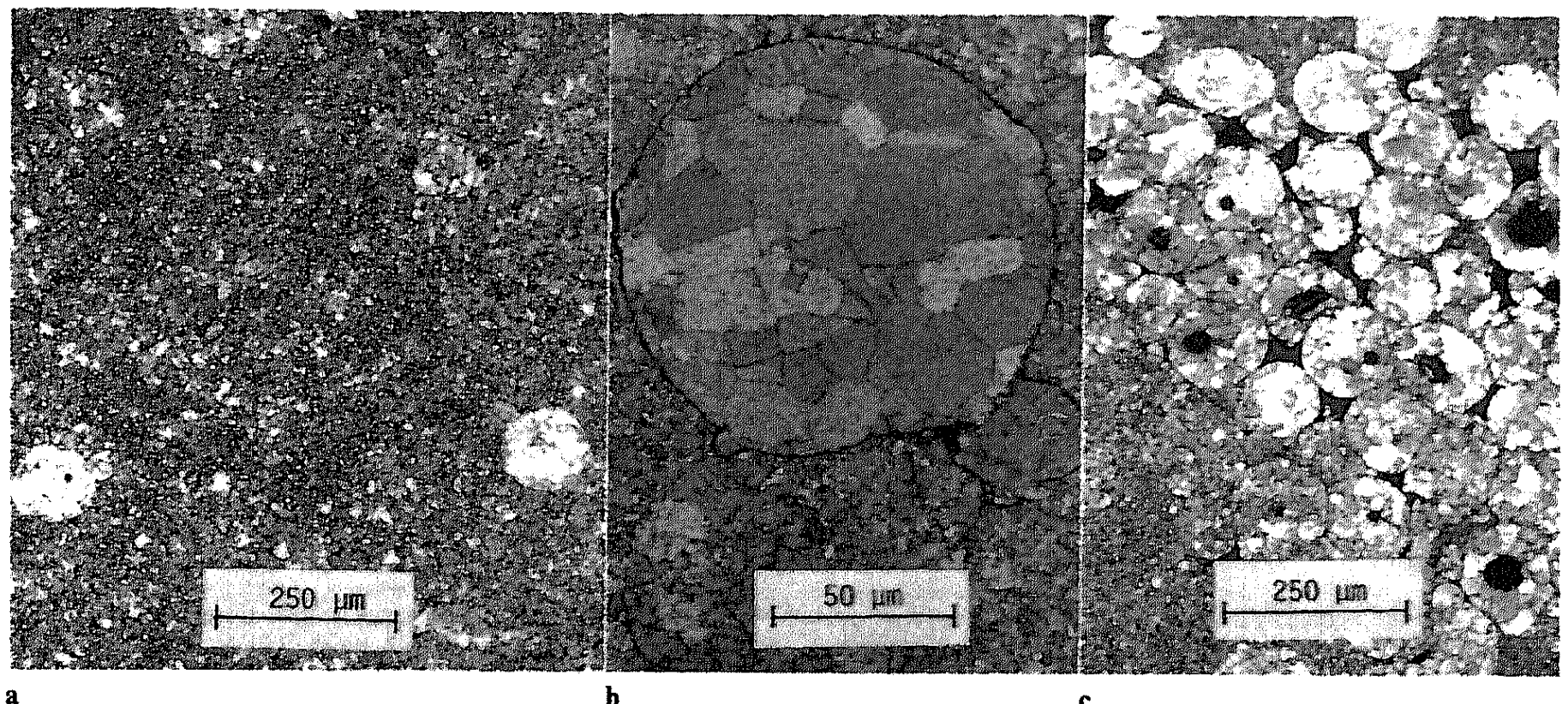

$a$ fine grained microstructure with some undeformed coarse particles; $b$ coarse grained particle at higher magnification; $c$ area of undeformed, coarse grained particles near corner of hipping container

10 Microstructure of AP1 superalloy after hipping at $1120^{\circ} \mathrm{C}$ at $50 \mathrm{MPa}$ for $20 \mathrm{~min}$ : particle size range $125-160 \mu \mathrm{m}$

the densification during hipping results in minor deformation of the larger central particle (Fig. 11b). An arrangement such as that shown in Fig. $11 a$ can occur frequently in normal particle size distributions. The particle size distributions of the AP1, and in particular the C1018, were very narrow, however, indicating that other geometrical arrangements may also be responsible for the development of the microstructural inhomogeneities. It is possible, for example, that a few particles were deformed only slightly during the initial stages of hipping owing to pockets in the powder particle arrangement. If the surrounding matrix of deforming particles softens owing to dynamic recrystallisation the initially undeformed particle will remain as a relatively hard spherical inclusion in a softer (with respect to the deformation during hipping) matrix.

\section{FINAL STAGE SINTERHIPPING OF W(Ni)}

Final stage sintering starts when the break up of interconnected pore channels leads to isolated pores which lie along junctions between three or four grains. ${ }^{12}$ During the final stage of sintering densification (pore shrinkage) and coarsening (pore coarsening and grain coarsening) occur simultaneously. Shrinkage occurs mainly by migration of vacancies from the pores along the grain boundaries to vacancy sinks (grain boundaries and free surfaces). During grain growth pores either remain at the boundaries or become separated and 'trapped' inside the grains. Pores that are trapped usually shrink at much lower rates than pores which are at grain boundaries, since bulk diffusivity is much smaller than grain boundary diffusivity. The separation of pores and grain boundaries usually starts at densities $>90 \%$. Totally closed porosity, however, is expected at densities $>93 \%$. As a consequence, pore-grain boundary separation may occur during sintering in a sinterhip treatment, as shown for W(Ni) in Fig. 12a. As shown in Fig. $12 b$, the application of $200 \mathrm{MPa}$ at $1400^{\circ} \mathrm{C}$ changes the microstructure dramatically: all pores were eliminated in the wake of migrating grain boundaries. It can be shown that in W(Ni) densification by other mechanisms (e.g. power law creep, which is most frequently observed in other systems and which depends on the bulk diffusivity) is small compared to pore shrinkage by vacancy transport along the grain boundaries and their subsequent elimination. ${ }^{13}$
The pore-grain boundary breakaway diagram shown in Fig. 13 can be used to explain pore-grain boundary interaction during sintering and hipping. There are two regimes where pores can remain attached to the grain boundaries. Pores which are immobile but large enough retard the motion of the boundary (pore control in Fig. 13). ${ }^{13-13}$ In the boundary control regime pores are small enough to move with the grain boundaries without impeding their motion. The intersection of the two poreboundary interaction regimes leads to a pore-boundary separation region with $G^{*}$ as the smallest grain size where grain boundary-pore separation occurs.

(a)

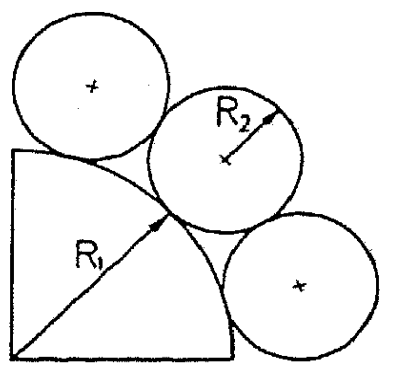

(b)

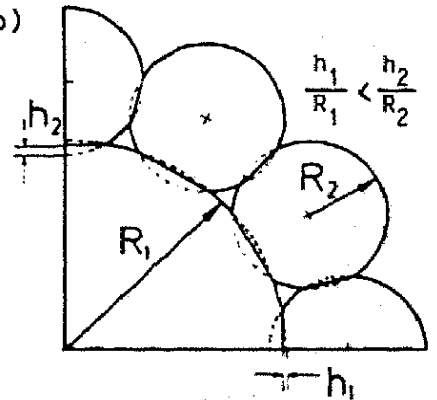

$a$ before contact deformation; $b$ after contact deformation and centre approach

11 Schematic diagram of deformation behaviour of small particles in contact with larger particles 


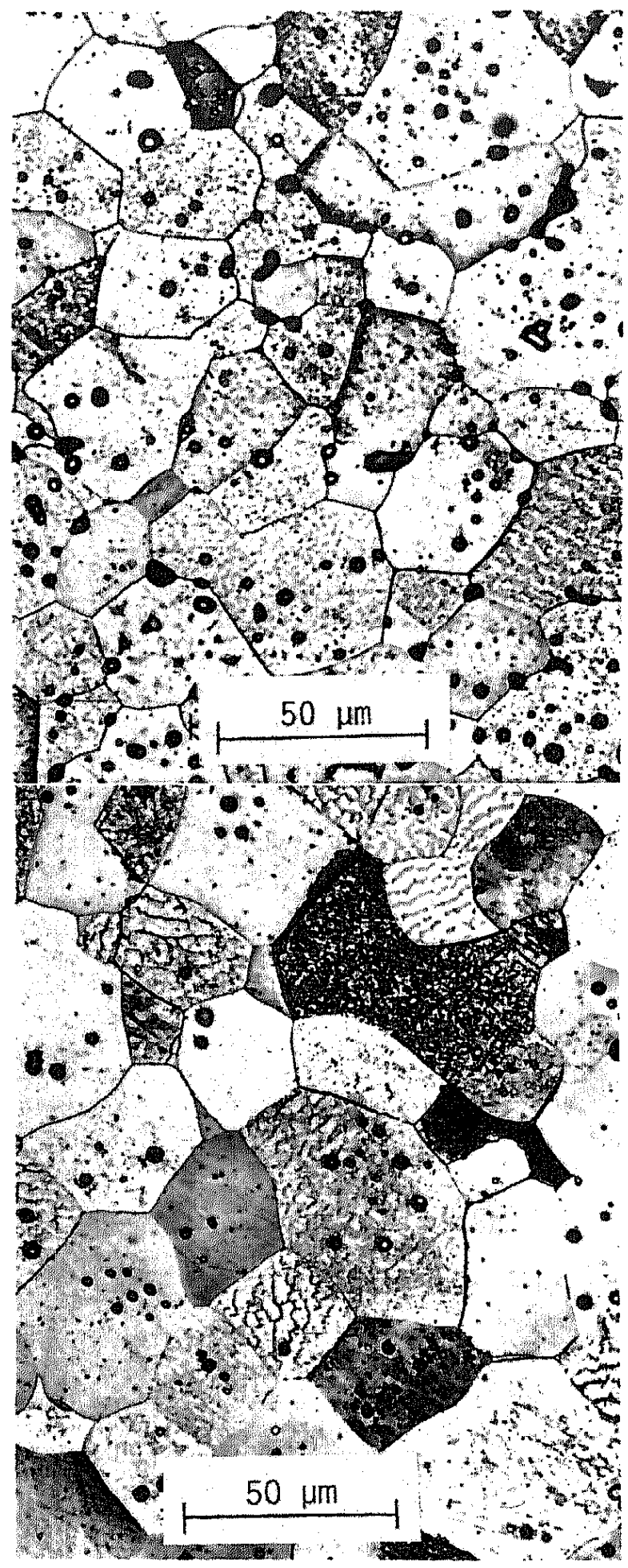

$a$ after sintering at $1400^{\circ} \mathrm{C}$ for $60 \mathrm{~min} ; b$ after hipping treatment at $1400^{\circ} \mathrm{C}$ for $60 \mathrm{~min}$ at $200 \mathrm{MPa}$

12 Microstructure of $\mathrm{W}-\mathbf{0} \cdot \mathbf{1 5 N i}$ after sintering and subsequent hipping

The final stage of $\mathrm{W}(\mathrm{Ni})$ sintering is characterised by extensive grain boundary-pore separation since grain boundary diffusion is dramatically increased by the presence of nickel at the grain boundaries. This also results in increased grain boundary mobility. When the samples are subjected to high hydrostatic pressure, as during hipping, the surface and grain boundary diffusion constants remain essentially constant, but the applied pressure gives much steeper vacancy chemical potential gradients and results in faster vacancy flow toward the grain boundary sinks. As a consequence, pores which come into contact with a moving grain boundary during hipping

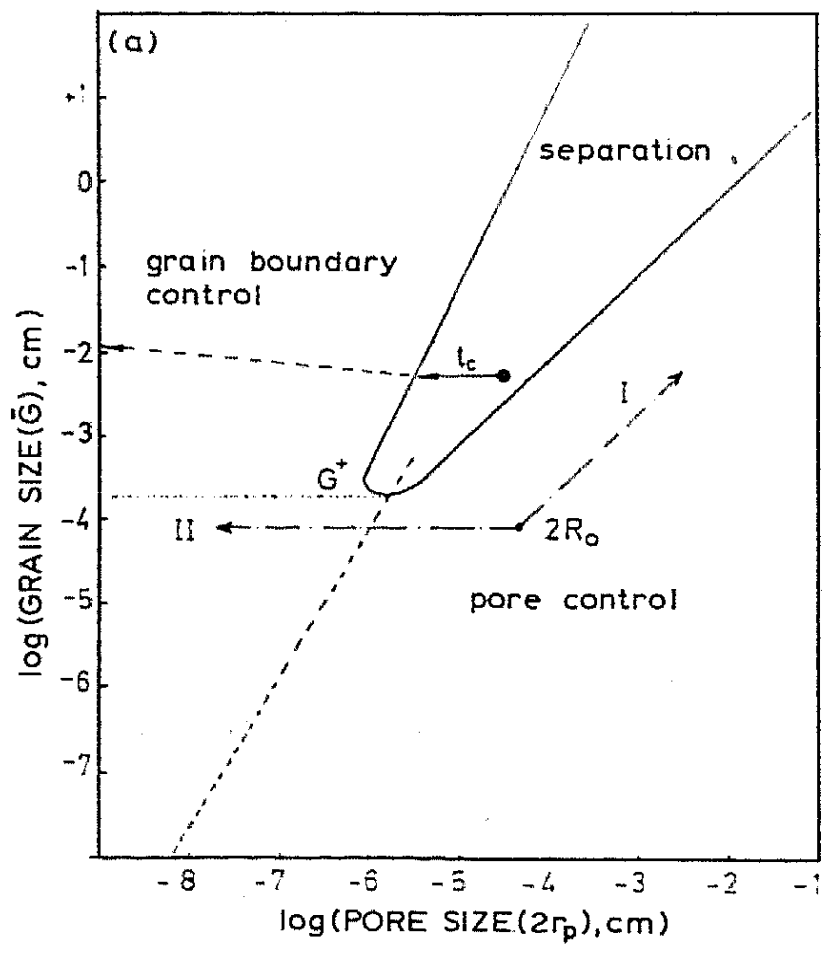

(b)

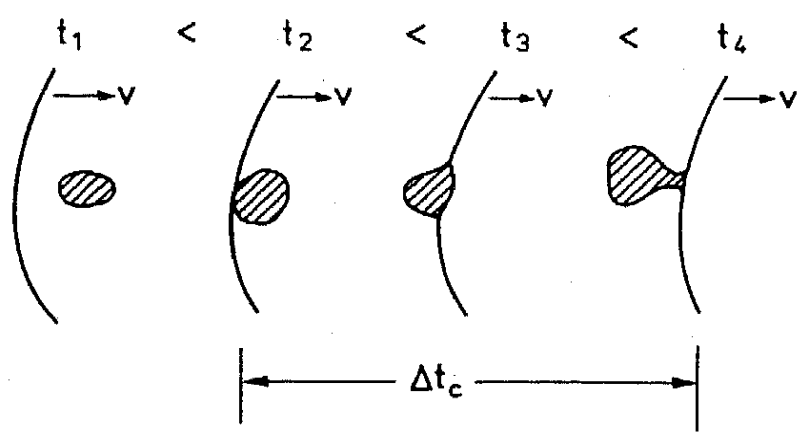

$a$ pore-grain boundary separation programme; $b$ grain boundary-pore interaction, consisting of contact between migrating grain boundary and pore followed by migration to breakaway position

13 Pore-grain boundary separation during final stage of sintering and hipping

shrink in a short time interval $t_{\mathrm{c}}$ to a size at which boundary control becomes dominant. If this time interval is shorter than the time which elapses before the contacting grain boundary migrates to a breakaway condition complete elimination of the pore will occur during further migration under the boundary control regime conditions (Fig. 13b).

\section{SUMMARY}

Measuring the deformation of single spheres is a useful method for predicting the hipping behaviour of new materials and reducing research and development costs. Some of the creep parameters can be determined quantitatively by the same method.

During final stage hipping at densities $>98 \%$ a small number of relatively large pores, about one third the particle radius in size, are still present.

During hipping, some fraction of the particles undergo only minor deformation. It was found for AP1 superalloy that these particles possessed coarse grain sizes, whereas the more heavily deformed particles displayed a fine microstructure. 
During the final stage of hipping nickel doped tungsten. complete pore elimination occurs when pores come into contact with grain boundaries migrating as a result of normal grain growth. The absence of power law creep allows description of the pore-grain boundary separation condition in terms of a critical time interval $t_{c}$ which elapses between the first contact of the grain boundary with the pore and the instant when the grain boundary has moved into the breakaway position.

\section{ACKNOWLEDGMENT}

We thank Deutsche Forschungsgemeinschaft (WAK, MA) and Internationales Büro der KFA-Jülich (MM) for financial support. Nuclear Metals, Concorde, MA kindly provided the $\mathrm{C} 1018$ powder.

\section{REFERENCES}

1. R. L. COBLE: J, Appl. Phys, 1970, 41, 4798.

2. F. W. GROSSMAN and M. F. ASHBY: Acta Metall., 1975, 23, 425.

3. D. S. WILKINSON and M. F. ASHBY: Acta Metall., 1975, 23, 1277.

4. D. S. WILkINSON: PhD thesis, Cambridge University, 1977.
5. M. F. ASHBY and H. J. FROST: 'Deformation mechanism maps"; 1982. Oxford. Pergamon.

6. A. $\$$. HELLE, K. E. EASTERLING; and $M$. F. ASHBY: Technical Report O2T. University of Lulea. 1985.

7. E. ARZT. M. F. ASHBY, and K. E. EASTHRLiNG: Metall. Trams... 1983, 14A, 211 .

8. F. B. SWINKELS, D. S. WILKINSON, F. ARZT, and M. F. ASHBY: AC'a Metall., 1983, 31, 1829 .

9. E. ARzr: Acta Metall. 1982, 30, 1883

10. O. MOLERLS: Powder Technol., 1975, 12, 259.

11. M. MITKOY, W. A. KAYSSER, and G. PETZOW: in 'Sintering '85', (ed. G. C. Kuczynski et al.); 1986, New York, London. Plenum.

12. K. LematSe, R. M, CANNON, R. D. DAGLEy, M. F, YAN, U. CHOWDRY, and H. K. BoweN: Proc. Int. Symp. on 'Factors in densification of oxide non-oxide ceramics", Hakone, Japan. 1978, (ed. S. Somiya), 190.

13. W. A. Kaysser, M. MItKov, and G. PEtzow: Proc. Colloq, on 'Unconventional forming processes in powder metallurgy', Paris, September 1984, Société Française de Métallurgie.

14. R. J. BRoOK: J. Am. Ceram. Soc., 1969, 52, 56.

15. C. H. HSUEF, A. G. EVANS, and R. I. COBLE: Acta Metall., 1982. 30, 1269.

\section{Biographical details of authors}

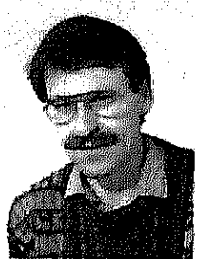

\author{
Dr Wolfgang A. Kaysser \\ Max-Planck-Institut für Metall- \\ forschung, Institut für Werkstoff- \\ wissenschaften, Pulvermetal- \\ lurgisches Laboratorium, Stuttgart, \\ FRG
}

Dr Kaysser was born in 1950. He received his Dipl-Ing and $\mathrm{PhD}$ degrees from the University of Stuttgart in 1975 and 1978 respectively. $\mathrm{He}$ is now senior researcher at the Powder Metallurgical Laboratory of the Max Planck Institute for Metals Research in Stuttgart. Since 1979, he has supervised a group of 10 people working on sintering, hot isostatic pressing, and atomisation. His major research areas of interest are: solid state sintering with additives; final stage solid state sintering; densification and homogenisation during liquid phase sintering; prediction of densification and microstructural development during hot isostatic pressing; effect of cooling rate and undercooling on the microstructure of atomised aluminium and copper alloys. He has published over 100 papers in the field and is the scientific editor of Powder Metallurgy International.

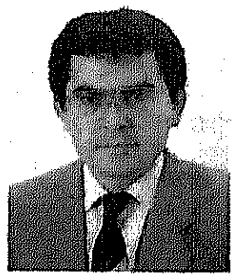

\author{
Dr Mesut Aslan \\ Max-Planck-Institut für Metall- \\ forschung, Institut für Werkstoff- \\ wissenschaften, Pulvermetal- \\ lurgisches Laboratorium, Stuttgart, \\ FRG
}

Dr Aslan was born in 1960 in Bafra, Turkey. After his education in Turkey he studied extractive metallurgy at Berlin Technical University, from where he received his Dipl-Ing in 1984 and his PhD in Material Science in 1987. Since 1984 he has been carrying out research at Max Planck Institute for Metals Research, Powder Metallurgy Laboratory, in Stuttgart on the theory and practice of hot isostatic pressing. Presently he is working in the field of high $T_{\mathrm{c}}$ ceramic superconductors.

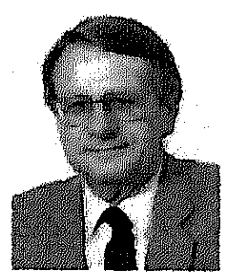

\author{
Professor Dr Günther Petzow \\ Max-Planck-Institut für Metall- \\ forschung, Institut für Werkstoff- \\ wissenschaften, Pulvermetal- \\ lurgisches Laboratorium, Stuttgart, \\ FRG
}

Professor Petzow studied Chemistry and Physical Metallurgy at the University of Stuttgart and the Max Planck Institute for Metals Research. He received his master's degree (Dipl-Ing) in 1956 and finished his $\mathrm{PhD}$ thesis (Dr rer nat) on 'Phase equilibria of quaternary metallic systems' in 1959. He is now a member of the Board of Directors of the Max Planck Institute for Metals Research in Stuttgart and Head of the Powder Metallurgy Laboratory and the Advanced Ceramics Facilities. He is also professor at the Universities of Stutgart and Berlin, where he teaches courses in equilibrium phase diagrams and powder metallurgy. His main scientific interests are concerned with problems in the field of physical metallurgy, powder metallurgy, and special ceramics and with phase diagrams of metallic and ceramic materials.

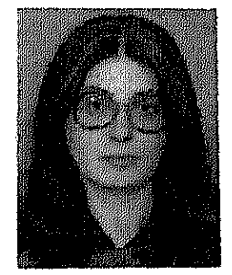

\section{Dr Mirjana Mitkov}

Institute Boris Kidrič

Belgrade, Yugoslavia

Dr Mitkov obtained a MSc in Physical Metallurgy from the University of Belgrade. After joining the PM research group at the Max Planck Institute for Metals Research in Stuttgart she obtained the Dr rer nat degree from the University of Stuttgart in 1977. Since obtaining her doctorate she has been a research fellow in PM of high temperature materials at the Boris Kidric Institute, Belgrade. Part of the present work was performed when Dr Mitkov was a visiting scientist at Stuttgart. 